\title{
Low Dose Gamma Ray Exposure in Mandala
}

\author{
Niki Saraswati \\ Faculty of Marine and Fisheries, University of Udayana, Bali, Indonesia
}

Email address:

saraswatiniki@gmail.com

\section{To cite this article:}

Niki Saraswati. Low Dose Gamma Ray Exposure in Mandala. International Journal of High Energy Physics. Vol. 2, No. 6, 2015 , pp. 61-68. doi: $10.11648 /$ j.ijhep.20150206.11

\begin{abstract}
This paper carries out a study on low dose gamma ray exposure in mandala. The objective of this research is to explain in scientific terms a phenomenon in a very unnatural circumstance which will relate the radiation of color energy and frequency of mandala effects resembling the descriptive properties of matter interaction of gamma radiation. There are three natural sources of gamma radiation, the gamma decays in radio isotopes, cosmic ray in high-frequency level and rare terrestrial gamma-ray flashes. These aforementioned sources of gamma radiation have high-energy photons and huge production of electrons which are generally dangerous and biologically hazardous. Emission of X-ray photons has photoelectric effect that penetrates to the bones and unsafe irradiation procedures may cause burns and cancer. Another classic observation of photoelectric effect occured in metals emitting electrons when light shines upon them such as in solar panel technology. While in low-intensity, it is possible that light can eject electrons through discrete packet of photon energy, linking energy and frequency to quantify energy. Without reaching and exceeding the threshold of frequency, there are no electrons reducing or increasing the energy transfers in any chemical interaction regardless of the amplitude and exposure to light. In physics, this light can be the gamma rays, X-rays, microwaves and radiowaves that emits and absorbs tiny packets identified as "photons". The relevance of this research paper encourages mandala energy as the medium for further studies and test theories on low-gamma radiation healing with anti-ageing benefits, the prototype and its effects is self-explanatory related to perpetual motion mechanics theorized in graviton and its technology may support manufacturing industries related to medicine, food production, energy and supply of clean water.
\end{abstract}

Keywords: Photoelectric Effect, Low-Dose Gamma Ray, Graviton

\section{Introduction}

The human body immune system is designed to protect the entire system against auto-immune diseases, inflammatory diseases and cancer [1-2]. Part of the defense mechanism has played active roles for antibody and antioxidant. Antibodies are released from the plasma cells to neutralize toxins, incapacitate virus and prevent them from infecting new cells [3]. Plasma cell, short-lived antibody producing cell derived from a type of leukocyte (white blood cell) called a B cell. B cells differentiate into plasma cells that produce antibody molecules closely modeled after the receptors of the precursor B cell. Once released into the blood and lymph, the antibody molecules bind to the target antigen (foreign substance) and initiates its neutralization or destruction or destruction [4]. White blood cells called lymphocytes originate in the bone marrow but migrate to parts of the lymphatic system such as the lymph nodes, spleen, and thymus. There are two main types of lymphatic cells, T cells and B cells. The lymphatic system also involves a transportation system - lymph vessels - for transportation and storage of lymphocyte cells within the body. The lymphatic system feeds cells into the body and filters out dead cells and invading organisms such as bacteria [5]. Oxidation is a chemical reaction involving the loss of electrons, when the chain reaction occurs in a cell, it can cause damage or death to the cell. Antioxidants terminate these chain reactions by removing free radical intermediates, and inhibit other oxidation reactions. Antioxidants are reducing agents such as thiols, ascorbic acid (vitamin C) or polyphenols [6].

Several medical cases had been treated by the mandala effects, citing two patients in 2014, one volunteered individual had an inflammatory disease in the eyes or commonly called sore eyes (conjunctivitis), another volunteer residing outside Bali was suffering from psoriasis, an autoimmune disease characterized by patches of abnormal skin, typically red, itchy and scaly. On the third day of advancement of disease, the patient's both eyes were affected with bacterial conjunctivitis, the doctor prescribed two eye drops for morning and evening 
treatment. The mandala treatment was tried to one of the eye, after 15 minutes, when the patient removed the mandala she felt the effect and stated that it stopped the gritty sensation and, watery discharge. She healed in five days and her husband with the same dilemma was cured after seven days. In psoriasis case, the patient was suffering from 10-year skin allergy, the boil worsened that affects most of the skin parts in the back and front leg to his toes, he already sought the doctor's advice and to his dismay had not alleviated his condition at all, not even the popular skin ointments can stop the itchiness when he eats egg and seafood. The mandala was sent to him to try it on the affected area, it can suppress the itchiness and the thick purple skin layers started drying and peeling. When there was progress within 7-days on $10 \mathrm{~cm} \times 10$ $\mathrm{cm}$ mandala, the larger A4-size was recommended to test the rate of chemical reaction, in his last testimony, he admittedly screaming from excruciating pain, he couldn't stand it, it peeled more damaged skin layers and softened the thick and callous layer. The last result was unknown due to lost of contact.

The medical cases above are not supported by further laboratory studies, although, there is an interesting published journal with same title research of the effects of low-dose gamma radiation in Anti-Ageing Medicine Journal, the "Low-dose Gamma Ray-irradiated Cells Activates Intracellular Antioxidant Systems via Purine Reports" by Shuji Kojima, Erina Takai, Mitsutoshi Tsukimoto of Faculty of Pharmaceutical Sciences, Tokyo University of Science (TUS), it activated the release of ATP and Antioxidant systems via purine receptors. They reported that Trx-1 is induced by low-dose gamma ray irradiation in lymphocytes, revealed the increase of GSH levels in immune cells subsequently activates the proliferation of lymphocytes and natural killer (NK) cells, thereby leading to the suppression and/or delay of the solid-tumor growth and colony formation observed in metastatic cancer [7]. The comparative research in "Low-dose Gamma Ray-irradiated Cells Activates Intracellular Antioxidant Systems via Purine Reports" will support the alleged claim of the healing effects in "Low Dose Gamma Ray Exposure in Mandala", the natural killer cell (NK) are part of the immunity system that provides rapid responses to viral-infected cells [8]. There are other mandala trials which can be beneficial in health and preventing illnesses, the mandala chemical reaction on raw, fresh, cooked and frozen food products, fruits, vegetables and meat.

\section{Description of the Phenomena}

\section{Mandala Food and Beverage Taste-Test}

The photoelectric effect in mandala was hinted during the first beverage taste-test to a local brand of red wine. Will you assume something different after placing the wine on top of the paper for 15 minutes? Eventually, the wine tasted sour. This bottle and two different mandala were brought into two separate meetings with total of five individuals providing the oral and written testimonial about the changes occured in the taste of the red wine, they detected sourness, bitter, tinge of salty and spicy flavor [9]. Presumably, the red wine underwent chemical changes once exposed in the low-gamma radiation in the mandala, below the threshold of frequency, no chemical reaction and changes would happen to the wine, as ordinary coasters are incapable of changing the taste of a patent formula. This inspired to conduct similar test on several mandalas to study the distinctive effect on each mandala and naturally to find the more balanced effect, one mandala fulfilled the desired level. Referring to this mandala as Mandala A, the list of coffee-taste test were the Balinese arabica coffee and various local coffee-mixed products, a pack with creamer and sugar pack.

Caffeine, a central nervous stimulant is the most widely used psychotropic drug in the world (Gilbert, 1948) [10]. Beverages containing caffein can prevent drowsiness and increase one's energy level ${ }^{[11]}$. Brewed coffee from grounds prepared with tap water contains $40 \mathrm{mg}$ caffeine per 100 gram [12], toxic doses are over 10 grams per day for an adult [13]. Aside from property test, these experiments were lacking scientific validation.

Table A. Coffee Taste-Test.

\begin{tabular}{|c|c|c|c|}
\hline No. & Type & Recipe & $\begin{array}{l}\text { Taste After } 5 \text { minutes on top } \\
\text { of Mandala }\end{array}$ \\
\hline 1. & $\begin{array}{l}\text { Balinese } \\
\text { Arabica } \\
\text { coffee }\end{array}$ & $\begin{array}{l}11 / 2 \text { tablespoon coffee, } \\
11 / 2 \text { tablespoon sugar }\end{array}$ & $\begin{array}{l}\text { The mandala effect caused the } \\
\text { coffee to taste sweeter }{ }^{[14]} \text {. }\end{array}$ \\
\hline 2. & $\begin{array}{l}\text { Kopi } \\
\text { Saset } \\
\text { Goodday }\end{array}$ & $\begin{array}{l}\text { Mixed pack of vanilla } \\
\text { flavored coffee, creamer } \\
\text { and sugar, good for one } \\
\text { cup }\end{array}$ & $\begin{array}{l}\text { The taste of coffee is stronger, } \\
\text { more full body not sweet }{ }^{[15]}\end{array}$ \\
\hline 3. & $\begin{array}{l}\text { Kopi } \\
\text { Luwak }\end{array}$ & $\begin{array}{l}\text { Mixed pack of civeat } \\
\text { flavored coffee with } \\
\text { creamer and sugar, good } \\
\text { for one cup }\end{array}$ & $\begin{array}{l}\text { The taste of coffee is lighter } \\
\text { than the other one }{ }^{[16)]}\end{array}$ \\
\hline 4. & $\begin{array}{l}\text { Kopi } \\
\text { ABC }\end{array}$ & $\begin{array}{l}\text { Mixed pack of black } \\
\text { coffee with sugar, good } \\
\text { for one cup }\end{array}$ & The taste of coffee is sweeter ${ }^{[17]}$ \\
\hline
\end{tabular}

In coffee taste-test, the method involved was to prepare two cups of coffee with the same portion of coffee, sugar and water or two packs of coffee-mixed. One cup was placed in the mandala for five minutes, sipping the coffee and memorized its taste, followed by the cup of coffee with the original taste. The individuals were not allowed to drink water in between coffee taste-test. From the four samplings, the indications were two black coffee increased the level in sugary taste, the two coffee mix creamer and sugar had an increased or reduced caffeine.

The Mandala A underwent adjustments in color and design updates, these two mandalas had different report in the alcoholic beverage taste-test.

The strength of an alcohol or spirit measured as the percentage of pure alcohol contained in the liquid. For instance, a whiskey of $40 \%$ ABV (alcoholic by volume) will contain $40 \%$ of pure alcohol, the rest being made up of water mainly plus various congeners [18]. Beer's alcoholic content is around $4 \%$ to $6 \%$ [19], wines exhibit broad range of alcoholic content from below $9 \%$ to above $16 \% \mathrm{ABV}$, the average being $12.5 \%-14.5 \%$ range [20]. 
Table B. Alcoholic Beverages.

\begin{tabular}{|c|c|c|c|}
\hline No. & Type & $\begin{array}{l}\text { Alcoholic } \\
\text { Content/Description }\end{array}$ & $\begin{array}{l}\text { Taste After } 5 \text { minutes } \\
\text { on top of Mandala }\end{array}$ \\
\hline 1. & $\begin{array}{l}\text { Heineken } \\
\text { Beer }\end{array}$ & Pale lager beer, $5 \%$ & $\begin{array}{l}\text { Mandala A: it tasted lighter than } \\
\text { the original taste }\end{array}$ \\
\hline 2. & Beer Bintang & Pale lager beer, $4.7 \%$ & $\begin{array}{l}\text { Mandala B: it tasted more full } \\
\text { body }\end{array}$ \\
\hline 3. & $\begin{array}{l}\text { Aga Hatten } \\
\text { Red Wine }\end{array}$ & $\begin{array}{l}\text { Medium bodied } \\
\text { wine, young wine, } \\
\text { Beaujolais-Nouveau }\end{array}$ & $\begin{array}{l}\text { Mandala B: Assesd as Burgandy, } \\
\text { with mandala, its taste } \\
\text { resembling a } 2 \text { year-old red wine. }\end{array}$ \\
\hline 4. & $\begin{array}{l}\text { Alexandria } \\
\text { Hatten White } \\
\text { Wine }\end{array}$ & Semi-sweet, fruity & $\begin{array}{l}\text { Mandala B: It tasted like French } \\
\text { white wine from Alsace, } \\
\text { northeast region of France. }\end{array}$ \\
\hline
\end{tabular}

Table C. Cooked Food.

\begin{tabular}{|c|c|c|c|}
\hline No. & Type & Description & $\begin{array}{l}\text { Taste After 5-15 minutes } \\
\text { on top of Mandala }\end{array}$ \\
\hline 1. & Salad & Green leafy salad & $\begin{array}{l}\text { The crisp freshness of the greens } \\
\text { are distinguishable; succulent }\end{array}$ \\
\hline 2. & $\begin{array}{l}\text { Mushed } \\
\text { Potatoes }\end{array}$ & With milk & It tasted so good \\
\hline 3. & Tartar Sauce & $\begin{array}{l}\text { Dip sauce for french } \\
\text { fries }\end{array}$ & $\begin{array}{l}\text { It tasted fine. The other mandala } \\
\text { made the mayonnaise tasted sour }\end{array}$ \\
\hline 4. & $\begin{array}{l}\text { Tenderloin } \\
\text { Steak }\end{array}$ & $\begin{array}{l}\text { Argentine } \\
\text { tenderloin, cooked } \\
\text { medium rare }\end{array}$ & $\begin{array}{l}\text { Longer than } 5 \text { minutes, the more it } \\
\text { gets tender. Juicy and succulent. }\end{array}$ \\
\hline 5. & $\begin{array}{l}\text { Mahi-Mahi } \\
\text { Fish Steak }\end{array}$ & Grilled & Tender but tasted a bit bland. \\
\hline
\end{tabular}

The method of test was the same, the glass of wine or beer is placed on top of mandala while another glass contains the original substance. The person who provided the testimonial in the Mandala Beverage-Taste Test is a French acquaintance who is involved in marketing the product and property in the tourism industry. The beverage taste-test of Heineken Beer with Mandala A and Beer Bintang with Mandala B had two different result, the Heineken Beer tasted lighter than its original taste and the taste of the Beer Bintang had a slight change to much stronger flavor.

Both property tests were not confirmed in further laboratory research. In wine taste-test, the Mandala B may have released an energy that gives maturity to the natural chemical balance of sweetness and acid in both red and white wine. Another notable effect of mandala was its capacity to keep cold beverages to stay cold longer, the cold beer using mandala coaster retained the quality of its taste for longer time.

The next conceivable idea was to run the test on cooked food at home, followed by the food taste-test in the restaurant.

The list above were the choices of salad and main courses in the menu, the dishes were placed in an A4-size mandala, there were 2 pcs of Mandala B available for this test, both were newly printed. The salad came first and the tenderloin steak, initial bites were taken to learn its original taste, the taste and quality of texture had changed in the next bite and the next bite. After more than 10 minutes, the tenderloin got more tender, there was no pressure in slicing the meat with the steak knife. The last entry dish was the Mahi-Mahi fish steak, the same process was taken, the mahi-mahi fish steak was so tender, it almost melt in your mouth. The dinner plate was bigger than the mandala, but it would confirm the hypothesis of the photolectric effect of gamma ray has the absorption proportional to the thickness of the layer, the density of the material and absorption cross section of th ematerial.

It can be understood, the mandala energy field has many functions, it can be a placemat, coaster and food storage placemat, with the next hypothesis that it might work on pre-cooked and fresh food.

Table D. Cold-Storage of Fresh Food.

\begin{tabular}{|c|c|c|c|c|}
\hline \multirow[b]{2}{*}{ Category } & \multirow[b]{2}{*}{ Type } & \multirow[b]{2}{*}{ Qty } & \multicolumn{2}{|l|}{ After Cooking Taste } \\
\hline & & & $\begin{array}{l}1-2 \text { days } \\
\text { in the freezer }\end{array}$ & $\begin{array}{l}3 \text { days more } \\
\text { in the freezer }\end{array}$ \\
\hline \multirow{3}{*}{ 1. Seafood } & $\begin{array}{l}\text { 1.1 Shrimp (1 1/2 inches } \\
\text { long) }\end{array}$ & 200 grams & $\begin{array}{l}\text { fresh and sweet; the meat head is still intact; the } \\
\text { meat is succulent }\end{array}$ & the meat is still succulent \\
\hline & 1.2 Squid & 3 pes. & So tender & \\
\hline & 1.3 Fish (5-6 inches long) & $\begin{array}{l}2 \text { pcs }-5 \text { pcs for } \\
\text { each type }\end{array}$ & it resembles the taste of chicken or meat of big & $\begin{array}{l}\text { the taste of freshness is reduce but the meat is } \\
\text { still succulent, intact at moment of frying }\end{array}$ \\
\hline 2. Meat & 2.1 Local Beef & 200 grams & $\begin{array}{l}\text { the meat is tenderized almost at par with the } \\
\text { quality of imported tenderloin, it is more tender } \\
\text { with the placemat treatment after cooking }\end{array}$ & \\
\hline \multirow[t]{2}{*}{ 3. Vegetables } & 3.1 Leafy Vegetables & & $\begin{array}{l}\text { the leaves stay fresh, succulent if cooked in } \\
\text { half-done }\end{array}$ & $\begin{array}{l}\text { It still maintains the quality of freshness } \\
\text { when you cook it properly }\end{array}$ \\
\hline & 3.2 Green Beans & & It is crisp when half-cooked & It is crisp when half-cooked \\
\hline
\end{tabular}

There are important lessons on distinguishing fresh food products before purchasing. Fresh whole fish should have bright, clear eyes, skin should be shiny, firm and elastic to the touch, gills should be red not brown, and if gutted, the cavity should be clean [21]. Absence of black spots shows that the shrimps are still fresh. Smell is another way to determine good shrimp, fresh seafood should smell of the sea as opposed to the fishy smell. The fishy smell signals that the decomposition has begun. The cooked shrimps need to be judged by its texture, rubbery or just right [22]. Most supermarkets will be very particular in selling fresh food products to avoid customer complaints on poor quality and condition of the stock.

The objective on the next experiment should test the mandala effect on grade B products, sold in food vendor in the neighborhood. Fish, meat, shrimp and squid are stored in the chiller, they replenish the stock to replace the sold quantities, unsold stock will be stored again in the chiller, the freshness is not guaranteed. The vegetables were in good condition. Before storage, all goods must be cleansed and placed in the 
plastic container with a mandala ( 1 x 1 inches) on the bottom of the container, or the plastic container is arranged on top of the mandala ( $6 \times 6$ inches). The method of cooking was deep-fry for fishes, pan-fry for beef, shrimps and squid, stir-fry to vegetables. Special note on the squid, the texture was so tender, not rubbery. The cooked fishes and shrimps has fresh sweet taste, not bland. This taste is only guaranteed by live-catch of fish and shrimps.

\section{History of Discovery}

"The religion of the future will be a cosmic religion. It should transcend a personal God and avoid dogmas and theology. Covering both the natural and the spiritual, it should be based on a religious sense arising from the experience of all things, natural and spiritual, as a meaningful unity. Buddhism answers this description." - Albert Einstein

Mandala is a product of the mind (frequency) expressed in the form of Buddhist art, it is a Sanskrit word which means the representation of the universe. The basic outline utilizes the Candi Borobudur's vertical lay-out plan, the variety of color contains energy waves. Candi Borobudur is the largest Buddhist monument in the world located in Central Java, Indonesia. Many anthropolgist and historian intellectuals were puzzled by the function of the Candi Borobudur.

The individual who can reveal the ancient Buddhist secrets is Niki Saraswati.

The first series of mandala borobudur designs were published in the book, Les Mandalas de Niki on 2011 in France, the co-writer conducted the functionality test for 12 months and became the guidelines on how to use the mandala in the book. It is still on sale in Amazon on-line store, France, UK, USA, Germany, Canada, Italy, Spain, India and Japan.

The latest Niki's mandala art was produced on 2012, it took more than 3 years of test and re-coloring to produce a very unusual effects that will coincide with many physics theories or correspond with the unsolved theory in physics, such as superstring theory, zero-energy point and perpetual motion mechanics in different perpective than the scientist's normal expectation.

It was an accidental discovery since year 2013 when a bottle of red wine was placed on top of mandala, the taste of locally manufactured red wine changed varily from too sour and hint of sweetness to different and existing mandala creation. The next following years, 2014-2015, this further lead to random experimentation of food taste-test and beverage taste-test on coffee, beer, whiskey, fruits, fresh, packaged and cooked food, to test the consistency of the chemical reaction, the consistency check is always positive.

Hence, the simple prototype using a paper material was reprinted several times which provided an insight of the consistency of the mandala effects.

\section{Hypothesis}

There are four questions to be able to establish the theory of low-dose gamma ray exposure in mandala, supported by other theories defined in zero-point energy, perpetual motion mechanic, gauge field and graviton, not withstanding these sub-supporting theories have not been applied in industrial uses unlike low-dose gamma radiation researches and experiments are all measurable and observable. The first cause of the photoelectric effect is the mandala image printed on a paper, the paper has no source of energy, it would fit into the theory of perpetual motion mechanics that has motions without any external source of energy [23].

1 . What kind of energy field in the mandala?

Zero-point energy, also called the quantum vacuum zero-point energy is the lowest possible energy, its the energy of its ground state. All quantum mechanical systems undergo fluctuations even in their ground state and have an associated zero-point energy, a consequence of their wave-like nature. The uncertainty principle requires every physical system to have a zero-point energy greater than the minimum of its classical potential well. This results in motion even at absolute zero [24]. The vacuum energy is not defined as empty space but the ground state of the energy fields in space of which includes the electromagnetic field, other gauge fields, fermionic fields and the Higgs field [25].

2. What is the color energy in Mandala?

The image is a free-hand drawing in a white paper, scanned, half or quarter piece of a circle are paired to create a symmetry of whole image, colors are applied on lines and spaces using adobe photoshop program installed in the computer. To provide coloring samples available in adobe photoshop, this computer software program also provides the tools to review the inverted and negative color, the table below will illustrate the 7-spectrum colors in the rainbow and its corresponding negative color in adobe photoshop.

Table E. Rainbow Colors and its Negative Colors.

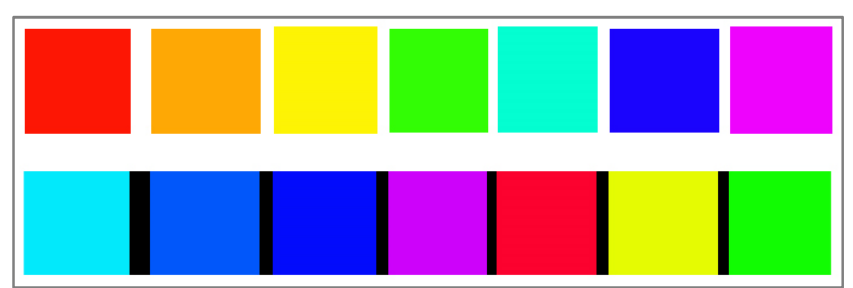

Assuming the energy field in mandala is the gauge field, particles have corresponding antiparticles. A particle with red, green, or blue charge has a corresponding antiparticle in which the color charge must be the anticolor of red, green, and blue, respectively, for the color charge to be conserved in particle-antiparticle creation and annihilation. Particle physicists call these antired, antigreen and antiblue. All three colors mixed together, or any of these colors and its complement (or negative), is "colorless" or "white" and has a net color charge of zero [26]. In quantum gauge theory of gravity, gravity is treated as kind of fundamental interactions, which is its transcendental starting point. In other words, it is a physical interaction of physical fields which is transmitted by graviton [27]. If there are graviton particles in mandala, it would explain the perpetual motion mechanics in the mandala 
energy field, to support this theory, would the mandala be qualifed for a closed-string model? A closed-string model is a string that no end points, and therefore is topologically equivalent to a circle. This circle is integral in the definiton of mandala in the Sanskrit philosophical beliefs, mandala's base is a circle that represents the universe. Like other quantum particles, gravitons can carry a lot of energy, or momentum, when confined to a small space, a graviton may pop-out from another graviton in a tiny space, one right next to the other. That huge amount of energy causes the newly-created graviton to create yet another graviton. This endless cycle of graviton production makes gravitons non-renormalizable [28] With the closed-string field and graviton particles, what proof the mandala has to offer? The mandala in this experiment was reprinted more than once during the 3-year observation of its effects, from the healing experiment, coffee experiment, alcoholic beverages, cooked and raw food, another graviton exists in the reproduction of mandala.

3. How long does it take to have an activation process in mandala?

The process takes place with the absence of activation of energy, also, there is no thermal energy from the mandala to activate the chemical reaction in room temperature or cold and hot food and beverages, they get the same photoelectric effect and momentum. Another finding in the hot and cold properties of the object, it stays hot and cold a little longer on top of the mandala, though, the experiment did not measure the temperature of those objects. The activation process can be explained in the theory model of energy - momentum, photons have zero rest mass, If the body is at rest $(v=0)$, i.e. in its center of momentum frame $(p=0)$, we have $E=E_{0}$ and $m=m_{0}$, thus, the energy-momentum relation and both forms of the mass-energy relation, all become the same [29].

Relatively, an object that fits the size of $2 \times 2$ inch size will have the same chemical interaction in $6 \times 6$ inches mandala, its reaction will have a momentum peak at 15 minutes. An object larger than the mandala with more than 4 inches in diameter, presumably would have a longer peak of 30 minutes to 60 minutes. The plastic food containers stacked on top of the mandala are slightly bigger than the printed paper, and another alternative for cold storage experiment was to place $1 \times 1$ inch size at the bottom of the plastic container. In the context of chemistry, the chemical transformation is accompanied by a change in structure, an increase or decrease of energy of the substances involved. A reaction is exergonic if the final state is lower on the energy scale than the initial state, its reverse situation is referred as endergonic reaction [30].

4. What are the other characteristics of the mandala energy which resembles the gamma ray characteristics?

The colored graphics image printed in the paper can alter the molecular structure of the object placed above it, its photoelectric effect can reduce or increase the energy to form a new balanced chemical change in food matter and liquid substances. When gamma ray passes through matter, the probability for absorption is proportional to the thickness of the layer, the density of the material and the absorption cross section of the material [31].

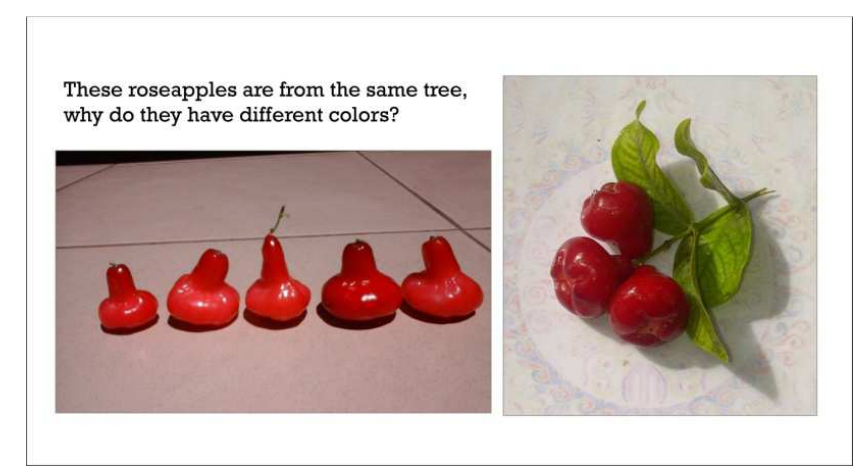

Photo 1. The two colors of the rose apples, the second photo is the temporal change.

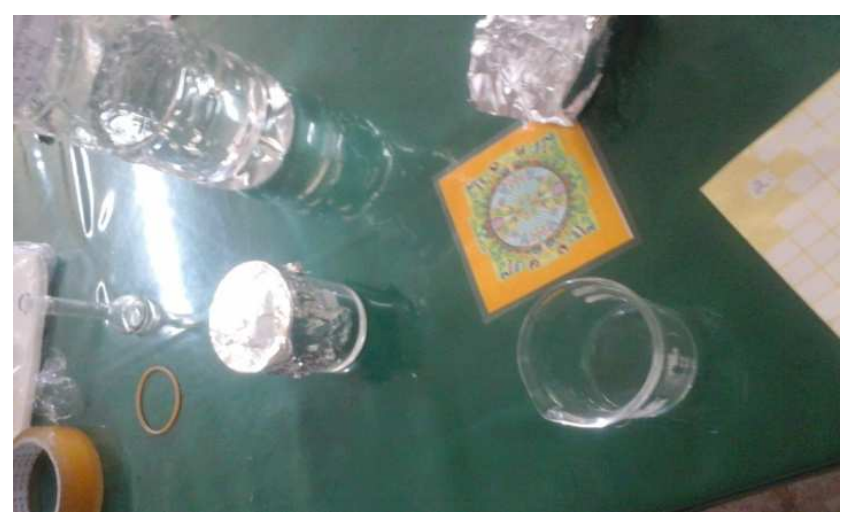

Photo 2. The mandala and the Ethanol.
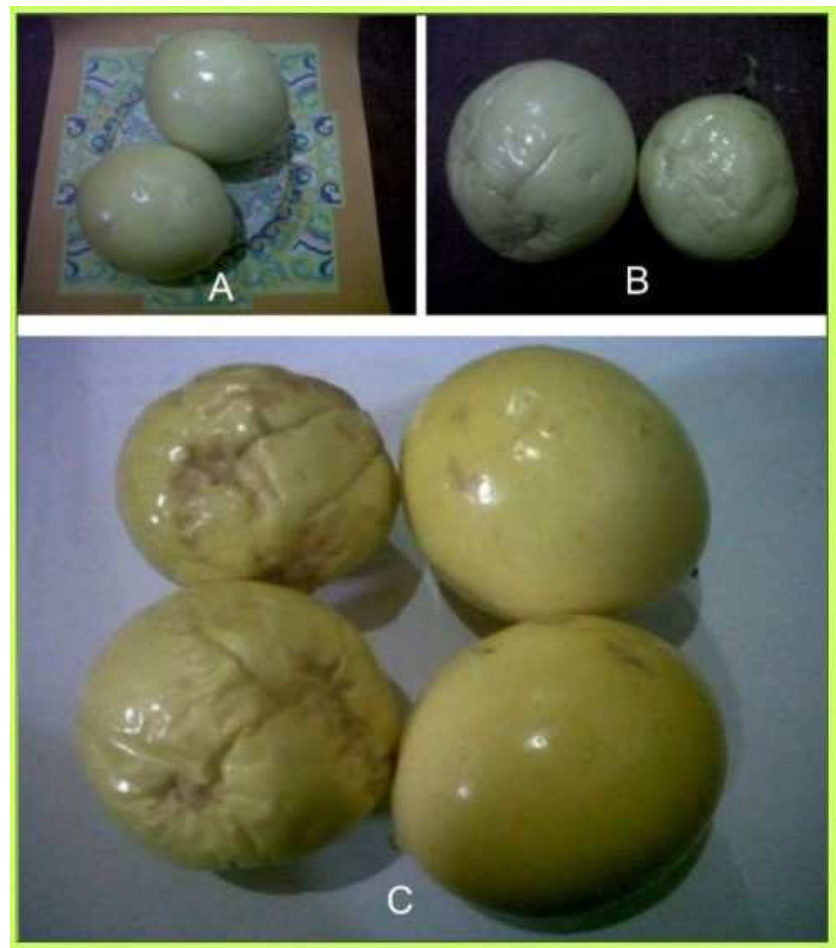

(A) 10-Day, (B) 4-Day, (C) 6-Day \& 12-Day

Photo 3. The marquisa fruit in the mandala.

Another finding in the chemical reaction of mandala water spray with the plants and trees, the rose apple fruits underwent a temporal change in its fruit-cycle, all colors have turned 
deeper-red. To observe the next phase of change, the treatment of mandala water was stopped and the next fruits returned to its normal pinkish color. Gamma induced molecular changes can also be used to alter the properties of semi-precious stones, and is often used to change white topaz into blue topaz [32].

The mandala water was tested its reaction on parasites infesting the plants, it eliminated the aphids [33]. During the cold-storage treatment for fresh food product, the mandala energy kept the freshness and made the food tastier after cooking and the fruits sweeter. Gamma radiation is often to used to kill living organisms in a process called irradiation, the removal of decay-causing bacteria from many foods and the prevention of the sprouting of fruit and vegetables to maintain freshness and flavor [34].

Curative effects has been observed in the mandala energy, it can heal wounds faster, immediately relieves pain, supports medication and healing process. It treated cases of sore eyes, boils, auto-immune skin disease, nose-bleeding, muscle/joint pains and reactivated disability of hand due to chemotherapy treatment. When gamma radiation breaks DNA molecules, a cell may be able to repair the damaged genetic material, within limits. However, a study of Rothkamm and Lobrich has shown that this repair process works well after high-dose exposure but is much slower than in the case of a low-dose exposure [35].

\section{Results and Discussions}

Ethanol Mandala Test

The testing took place on 29 July 2015 at Laboratory of Faculty of Marine and Fishery in Udayana University, the mandala in this experiment was newly printed. The validation of this research was witness and supported by Prof. Dr. Ir. Ida Bagus Manuaba, the head of the laboratory and Mr. Nyoman Nusada, chromatograph machine operator with more than 20 years experience in the university.

The ethanol was the distilled product from the Japanese beer, its ethanol count would be calculated in the chromatograph machine. One part of the ethanol was put above the mandala for 15 minutes while waiting for the result of ethanol count, followed by the ethanol treated by the mandala.

Table F. Chromatograph Machine Result.

\begin{tabular}{lll}
\hline Type & Time & Area \\
\hline Original Ethanol & 5.707 & 30505 \\
Mandala Treated Ethanol & 5.942 & 25208 \\
\hline
\end{tabular}

The initial state of ethanol was $13.17 \%$ or value of 13.17 , mandala energy has reduced the value to $10.88 \%$ (or 10.88 ), or at momentum of $2.25 \%$ with maximum time of 15 -minutes (900 seconds). This reaction is exergonic, the final state energy level is lower than initial state. The energy and momentum is calculated based on the following factors:

Mandala Energy $=0$, or $M E_{0}$ and $m=m_{0}$, thus, the energy-momentum relation and both forms of the mass-energy relation, is the same. After the chromatograph test, it revealed the values its mass, $\operatorname{mass} 1=m 1=13.17$, $\operatorname{mass} 2=m 2=10.88$, time frame is 900 seconds, $t=900$ seconds.

$$
\mathrm{ME}=(\mathrm{m} 1-\mathrm{m} 2) / \mathrm{t}=0.002544444 / \text { momentum per seconds }
$$

The equation above indicated the massless particle in the mandala energy field is moving slower than the speed of light.

$M E$ is relative, constant value in $t$ is established as the taste in food and beverage started to change from 5-minutes and peak in 15 minutes. The size or space in mandala is another factor of consideration for the chemical reaction rate of fast and slow, the object on top of mandala should be smaller than the mandala, the fastest rate of reaction would be 5-minutes and the slowest rate is/from 15 minutes.

For $E=m c^{2}$ equation, speed of light is converted from meter per second to centimeter per second, as the space in mandala is 10 centimeters in width and length, $s 2=100$ centimeters, this would be squared, the speed of light is moving at rate of $c 2=2,997,925$ centimeters per second, mass 3 or $m 3$ is the value of $M E=(m 1-m 2) / t=0.002544444$.

$$
\begin{gathered}
\mathrm{E}=((\mathrm{m} 3 * \mathrm{c} 2) \mathrm{s} 2)^{2} \\
\mathrm{E}=((0.00254 * 2,997,925) 100)^{2}=581,871,855,902.93
\end{gathered}
$$

The total energy of the particle in the speed of light $(299,792,458$ meter per second) is $581,871,855,902.03$. The imaginary number in the Lorentz equation with velocity factor has $E^{2}=p^{2} c^{2}+m^{2} c^{4}$.

Tachyon Relativistic Theory

In special relativity, a faster-than-light particle would have space-like four-momentum, in contract to ordinary particles that time-like four-momentum, it would have imaginary mass and proper time. Being constrained to the spacelike portion of the energy-momentum graph, it could not slow down to subluminal speeds [36].

Lorentz invariant theory has the same formulas that apply to ordinary slower-than-light particles (sometimes called "bradyons" in discussion of tachyons) must also apply to tachyons, this particular energy-momentum relation, where $p$ is the relativistic momentum of the bradyon and $\mathrm{m}$ is its rest mass) should still apply, along with the formula of the total energy of a particle.

$$
E^{2}=p^{2} c^{2}+m^{2} c^{4}
$$

This equation shows that the total energy of a particle (bradyon or tachyon) contains a contribution from its rest mass (the "rest mass - energy") and a contribution from its motion, the kinetic energy. When $\mathrm{v}$ is larger tha $\mathrm{c}$, the denominator in the equation for the energy is "imaginary", as the value under the radical is negative. Because the total energy must be real, the numerator must also be imaginary: i.e. the rest mass $m$ must be imaginary, as pure imaginary number divided by another pure imaginary number is a real number [37].

\section{Conclusion}

The manuscript title "Low Dose Gamma Ray Exposure in Mandala" is a deliberate assumption to project a 
non-hazardous gamma ray activity in mandala.

With the presented analysis of the mandala energy and its chemical reaction that can reduce or increase the energy to synthesize the final chemical balance, the color charge can be adjusted to a more desirable result with the evidence of differing effect in Mandala A and Mandala B report in the Table B. Alcoholic Beverages. Several mandala images were reprinted more than once during the entire period (2012 2015) to amount the scale of evidence, Mandala B's effect was validated officially in the chromatograph machine, the ethanol content reduction confirmed the assumption of the final state of the Heineken Beer, lighter than the original taste.

Theories on high-energy and weak-energy particles can only be measured in its actual use in the nuclear physics, quantum chemistry and other related branch of science and medicine. The assumption of the existence of gamma ray in the mandala has chemical reaction rate depending on the size of the mandala, the patient with a 10-year old skin-disease experienced a tremendous pain after it tried a larger size of mandala that almost cover the entire area, while the size of $2 \mathrm{x}$ 2 inches peeled the skin without the excruciating pain. There is a constant mandala energy value higher than the low-dose gamma ray exposure.

In the computational field of mandala energy, the factors involved are energy - momentum relation and $E=m c^{2}$, the chemical reaction and the speed of chemical reaction must be calculated initially to determine the exorgonic and energonic state, the initial state - final state $(i s-f s$ ), when the final state is higher than the initial state, the exergonic and energonic mass calculation will be transformed to non-reversible theory model of mass 1 is higher than mass 2 , to determine the momentum per second, thus, the theorem of $M E=(m 1-m 2)$ $/ t$ is only applied in mandala energy.

Further conversion is necessary when the size of the mandala is by centimeter, for $E=m c^{2}$ equation, speed of light is converted from meter per second to centimeter per second, as the space in mandala is 10 centimeters in width and length, $s 2=100$ centimeters, this would be squared, the speed of light is moving at rate of $c 2=2,997,925$ centimeters per second, mass 3 or $m 3$ is the value of $M E=(m 1-m 2) / t=0.002544444$.

$$
\begin{gathered}
\text { ME2 }=((\mathrm{m} 3 * \mathrm{c} 2) \mathrm{s} 2)^{2} \\
\mathrm{ME} 2=((0.00254 * 2,997,925) 100)^{2}=581,871,855,902.93
\end{gathered}
$$

The total energy of the particle in the speed of light $(299,792,458$ meter per second $)$ is $581,871,855,902.03$. The imaginary number in the Lorentz equation with velocity factor has $E^{2}=p^{2} c^{2}+m^{2} c^{4}$. To test the second equation of $M E 2=$ $((m 3 * c 2) s 2)^{2}$ must take another experiment with a 1 meter $\mathrm{x}$ 1 meter size of mandala.

The Einstein's photoelectric effect theory confirmed that there is an energy - frequency relation in the mandala energy, even in a low-intense energy but capable of increasing or reducing the atomic and molecular structure has reached the threshold of energy in the frequency of light, gamma-ray, $\mathrm{X}$-ray, infrared, radio wave and micro-wave.

With the potential energy in the imaginary total energy of the particle in the speed of light, the mandala can be reproduced carrying the same particles and energy, its uses vary that is similar to the construct and effects of the low-dose gamma radiation in other scientific experiment and researches, which is only beneficial to the health and well-being of the invidual human being and the environment, the prototype is a non-toxic material with no hazardous chemical content whatsoever.

\section{Acknowledgement}

This research paper would like to thank Prof. Dr. Ir. Ida Bagus Putra Manuaba and Mr. Nyoman Nusada from the Laboratory of Faculty of Marine and Fisheries of University of Udayana, Bali - Indonesia for sponsoring the scientific experiment of Ethanol Mandala Test.

There are lots of people I would like to thank for specially from the day I was born until today who motivated me to pursue the scientific experiment, this is for all the people in my family and friends who paved way for this research to materialize.

Also, thanking those who provided more motivation irregardless of disbelief in nature, during an exchange of verbal antic, I responded to a critic."If your product and technology is made of steel and stone, while mine is photoelectric product through an image which can be printed in any type of printing machine, on any material such as paper, laser-printing in plastic/fiberglass and canvas. Will you discriminate my product from black-magic recipe?"

How I wish I could tell that the source of enlightenment in religion is the Gamma Ray, God is zero-state universe with perpetual motion mechanics. Religion and spirituality is based on metaphysical beliefs, it's been my personal principle to prove it via physics.

\section{References}

[1] Beck, Gregory; Gail S. Habicht (November 1996). "Immunity and the Invertebrates" (PDF). Scientific American 275 (5): 6066. doi: 10.1038/scientificamerican1196-60. Retrieved 1 January 2007.

[2] O'Byrne KJ, Dalgleish AG (Aug 2001). "Chronic immune activation and inflammation as the cause of malignancy". British Journal of Cancer 85 (4): 473-83. doi:10.1054/bjoc.2001.1943. PMC 2364095. PMID 11506482.

[3] http://www.nobelprize.org/educational/medicine/immunity/im mune-detail.html

[4] http://global.britannica.com/science/plasma-cell

[5] http://www.nobelprize.org/educational/medicine/immunity/im mune-detail.html

[6] Sies H (Mar 1997). "Oxidative stress: oxidants and antioxidants". Experimental Physiology 82 (2): 291-5. doi: 10.1113/expphysiol.1997.sp004024. PMID 9129943.

[7] Kojima, S., Takai, E., Tsukimoto, M. (2011). "ATP Released from Low-Dose Gamma Ray-irradiated Cells Activates Intracellular Antioxidant Systems via Purine Receptors". http://www.anti-aging.gr.jp/english/pdf/2011/8\%287\%29108-1 13.pdf. 
[8] Vivier, E., Raulet, D.H., Moretta, A., Caligiuri, M.A., Zitvogel, L., Lanier, L.L., Yokoyama, W.M. \& Ugolini, S.; Raulet; Moretta; Caligiuri; Zitvogel; Lanier; Yokoyama; Ugolini (2011). "Innate or Adaptive Immunity? The Example of Natural Killer Cells". Science 331 (6013): 44-49. doi: 10.1126/science. 1198687.

[9] https://mandalaborobudur.wordpress.com/2014/04/30/mandala s-effect-on-wine-liquor/

[10] p. 69, Introduction, Suzette M. Evans, The New York State Psychiatric Institute, New York, New York 10032, Handbook of Substance Abuse Neurobehavioral Pharmacology, Edited by Tarter et.al, Plenum Press, New York 1998. ISBN 978-1-4419-3297-6@ Springer Science + Business Media New York, originally published by Plenum Press, New York.

[11] p. 44, "Function of Energy Drinks", Gerald P Krueger, Howard M Leaman, Gene Bergoffen, Daniel C Murray, Racquel Pickett, Effects of Psychoactive Chemicals on Commercial Driver Health, Washington, D.C.: Transportation Research Board@2011.

[12] Basic Report: 14209, Coffee, brewed from grounds, prepared with tap water a ndb.nal.usda.gov

[13] p. 368, Michael J. Mahoney, Abnormal Psychology on human variance, Harper \& Row, 1980 - Psychology - 590 pages.

[14] http://www.kompasiana.com/nikisaraswati/mandala-merubahrasa-kopi-tubruk_54f5ecc3a33311ef018b45a6.

[15] http://www.kompasiana.com/nikisaraswati/mandala-merubahrasa-kopi-saset-white-koffie-luwak 54f5ef31a333114d038b45 bc.

[16] http://www.kompasiana.com/nikisaraswati/mandala-merubahrasa-kopi-saset-white-koffie-luwak_54f5ef31a333114d038b45 bc.

[17] http://www.kompasiana.com/nikisaraswati/mandala-merubahrasa-kopi-saset-white-koffie-luwak_54f5ef31a333114d038b45 bc.

[18] http://www.celtic-whisky.com/glossary.htm.

[19] "World's strongest beer reclaimed". BBC News. 2010-02-16. Retrieved 2015-08-05.

[20] Jancis Robinson (2006). The Oxford Companion to Wine (3rd ed.). Oxford University Press.

[21] Shrimps: http://www.racsl.com/index.php?key=32.

[22] http://www.mjseafood.com/fishipedia-seafood-guide/buying-s toring-and-cooking/quality/.

[23] "Dictionary - Definition of perpetual motion". Websters-online-dictionary.org. Retrieved 2012-11-27.
[24] Kragh, Helge (2012). "Preludes to dark energy: zero-point energy and vacuum speculations". Archive for History of Exact Sciences (Springer-Verlag) 66 (3): pp 199-240. doi:10.1007/s00407-011-0092-3.

[25] Rugh, S. E.; Zinkernagel, H. (2002). "The Quantum Vacuum and the Cosmological Constant Problem". Studies in History and Philosophy of Modern Physics, vol. 33 (4): 663-705. arXiv:hep-th/0012253. doi: 10.1016/S1355-2198(02)00033-3.

[26] p. 1013, Color, Raymond Serway, Christ Vuille, College Physics, Cengage Learning, 1 Jan 2014 - 1136 pages.

[27] p. 86, Albert Reimer, Quantum Gravity Research Trends, Nova Publishers 2006 - 362 pages.

[28] http://io9.com/what-are-gravitons-and-why-cant-we-see-them1643904640

[29] D. Kleppner, R.J. Kolenkov (2010). An Introduction to Mechanics. Cambridge University Press. p. 500. ISBN 9-780521-198219.

[30] Pass the Teas V: Complete Teas 5 Study Guide with Practice Test Questions, Complete Test Preparations Inc., 7 Sep 2012 322 pages.

[31] p. 348, Robert Ehrlich, Waging Nuclear Peace: The Technology and Politics of Nuclear Weapons, SUNY Press 1985 - 397 pages.

[32] 2.1.5. Other Applications, p. 7, L.G. Gazsó, C.C. Ponta, Radiation Inactivation of Bioterrorism Agents, IOS Press, 25 Feb 2005, 216 pages.

[33] https://mandalaborobudur.wordpress.com/2015/01/05/mandala -fruit-plant-and-soil-therapy-second-series/

[34] 2.3 Food Irradiation, p. 9, L.G. Gazsó, C.C. Ponta, Radiation Inactivation of Bioterrorism Agents, IOS Press, 25 Feb 2005, 216 pages.

[35] Rothkamm K. - Evidence for a lack of DNA double-strand break repair in human cells exposed to very low x-ray doses Proceedings of the National Academy of Science of the USA, 2003; 100 (9) : 5057-5062.

[36] Feinberg, G. (1967). "Possibility of Faster-Than-Light Particles". Physical Review 159 (5): 1089-1105. Bibcode: 1967PhRv..159.1089F. doi:10.1103/PhysRev.159.1089. See also Feinberg's later paper: Phys. Rev. D 17, 1651 (1978)

[37] p.52, Chapter 2 Faster than Light Travel, Rupert W. Anderson, The Cosmic Compendium: Intertellar Travel, Lulu.com, 28 Mar 2015 - 456 pages. 